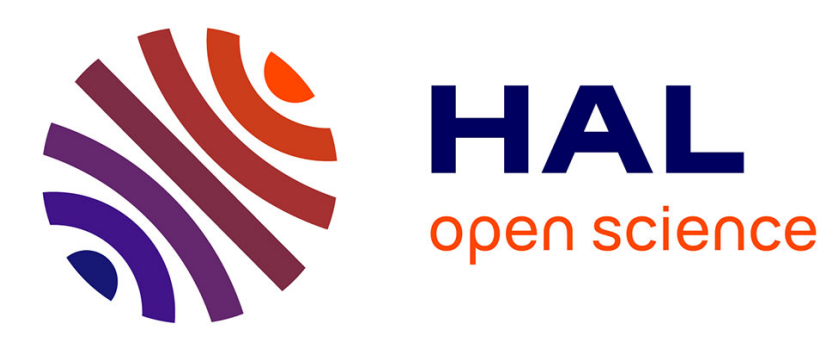

\title{
Micro EDM with the in situ electrochemical fabrication and regeneration of the tungsten microelectrode tool
}

\author{
G Girardin, Y Layouni, P Morin, M Cabrera
}

\section{To cite this version:}

G Girardin, Y Layouni, P Morin, M Cabrera. Micro EDM with the in situ electrochemical fabrication and regeneration of the tungsten microelectrode tool. 13th International ESAFORM Conference on Material Forming, Apr 2010, Brescia, Italy. hal-01306833

\section{HAL Id: hal-01306833 \\ https://hal.science/hal-01306833}

Submitted on 25 Apr 2016

HAL is a multi-disciplinary open access archive for the deposit and dissemination of scientific research documents, whether they are published or not. The documents may come from teaching and research institutions in France or abroad, or from public or private research centers.
L'archive ouverte pluridisciplinaire HAL, est destinée au dépôt et à la diffusion de documents scientifiques de niveau recherche, publiés ou non, émanant des établissements d'enseignement et de recherche français ou étrangers, des laboratoires publics ou privés. 


\title{
MICRO EDM WITH THE IN SITU ELECTROCHEMICAL FABRICATION AND REGENERATION OF THE TUNGSTEN MICROELECTRODE TOOL
}

\author{
G. Girardin ${ }^{1}$, Y. Layouni ${ }^{1}$, P. Morin ${ }^{1}$, M. Cabrera ${ }^{1 *}$ \\ ${ }^{1}$ Institut des Nanotechnologies de Lyon - UMR 5270 CNRS INSA ECL UCB - Université Claude \\ Bernard Lyon 1 -Bât. Léon Brillouin - 43, Boulevard du 11 Novembre 1918 - \\ F69622 Villeurbanne Cedex - France
}

\begin{abstract}
A new process for the fabrication of cylindrical microelectrode tools with high aspect ratio for microelectrical discharge machining $(\mu \mathrm{EDM})$ is reported. Tungsten micro-tools with a diameter ranging from $1 \mu \mathrm{m}$ to $26 \mu \mathrm{m}$ and aspect ratio ranging from 15 to 20 are obtained in about 30 minutes with a low cost and automated technique. This one is based on the electrochemical etching of the tool material with a process which has fully been integrated in a milling $\mu \mathrm{EDM}$ machine. As proof of interest, preliminary examples of $\mu$ EDM machining are also reported with the $26 \mu \mathrm{m}$ diameter tool. After $\mu \mathrm{EDM}$ machining, fast and automated in situ tool regeneration is also demonstrated. This may be of great help to simplify the tool wear compensation algorithm during $\mu$ EDM milling.
\end{abstract}

KEYWORDS: microelectrode, electrochemistry, micro EDM, microelectrical discharge machining, micromachining.

\section{INTRODUCTION}

The improvement of machining technique like micro electrical discharge machining $(\mu \mathrm{EDM})$ is still required in Microfabrication when 3D mesoscopic and/or high aspect ratio (i.e. the ratio of the part height with its lateral dimension) parts are needed. In addition, it is known that $\mu \mathrm{EDM}$ is compatible with all kinds of electrically conducting materials, which opens the way to machine unconventional (non-silicon) materials in Micro-technology. Examples of application of growing importance are the machining of stainless steel for the chemical micro-reactors and hard metals for the micromolds for injection molding. Processes like Reactive Ion Etching, Focused Ion Beam and LIGA are expensive and/or not optimized for these materials [1].

However, $\mu \mathrm{EDM}$ has still to be improved in terms of resolution. This is of paramount importance in the case of $\mu \mathrm{EDM}$ milling, which allows machining $3 \mathrm{D}$ parts by controlling the path of a cylindrical microelectrode tool. In this case, the miniaturization of the tool is a key factor for the machining resolution.

The manufacturing of theses tools has still to be largely improved in terms in tool diameter and aspect ratio. These tools are traditionally made by reverse EDM [2], wire EDM, WEDG [3] or micromilling but this requires a dedicated machine and the tool diameter is still limited at best to the $2-5 \mu \mathrm{m}$ range with important residual stress [4]. Therefore, in practice $10-20 \mu \mathrm{m}$ diameter tools are often used.

In this article, we shall report a new process for the fabrication of a microelectrode tool and its integration in a milling $\mu \mathrm{EDM}$ machine under development in our laboratory [5]. Our machine is made of two subssystems:

- The tool fabrication place

- The milling $\mu \mathrm{EDM}$ machine itself.

The tool which is typically a tungsten $\operatorname{rod}(250 \mu \mathrm{m}$ diameter $-20 \mathrm{~mm}$ height) is first prepared in the tool fabrication place and then translated to the $\mu \mathrm{EDM}$ machining place for further use. After machining, the tool can be returned to the tool fabrication place. In other respects, it is well known that tool wear in an important problem during the $\mu \mathrm{EDM}$ milling [2]. Therefore fast in situ tool regeneration will be also demonstrated in this work.

\section{TOOL FABRICATION}

The fabrication of the tool is based on the electrochemical etching of a cylindrical tungsten electrode. This process is derived from the techniques originally developed for preparing the tips of Scanning Tunneling Microscopes (STM) or Atomic Force Microscopes (AFM). The process has been modified to

\footnotetext{
* Michel Cabrera - INL - UMR 5270 CNRS UCB Lyon 1- Bât. Léon Brillouin, 43, Boulevard du 11 Novembre 1918, F69622 Villeurbanne Cedex - France ; Phone: +33 (0)4 72431433 - Fax: +33 (0)4 72432740 - Email : Michel.Cabrera@univ-lyon1.fr
} 
avoid the conical shapes with atomic apex needed for STM and AFM. Our goal was to obtain the cylindrical microelectrode tools with high aspect ratio which are necessary for the $\mu \mathrm{EDM}$ milling.

\subsection{SET UP}

The process is based on the electrochemical etching of the tungsten rod. This one is immersed in a vat filled with $\mathrm{NaOH}$ electrolyte at $1 \mathrm{Mol} / \mathrm{L}$ (mixed with $50 \%$ glycerol) together with a cylindrical counter-electrode grid placed around the rod. The vat contains also a supporting dielectric liquid (non miscible with the electrolyte) and also a small container filled with Gallium-Indium. The electrical contact is performed by putting in contact the end of the rod with the Ga-In (Figure 1)

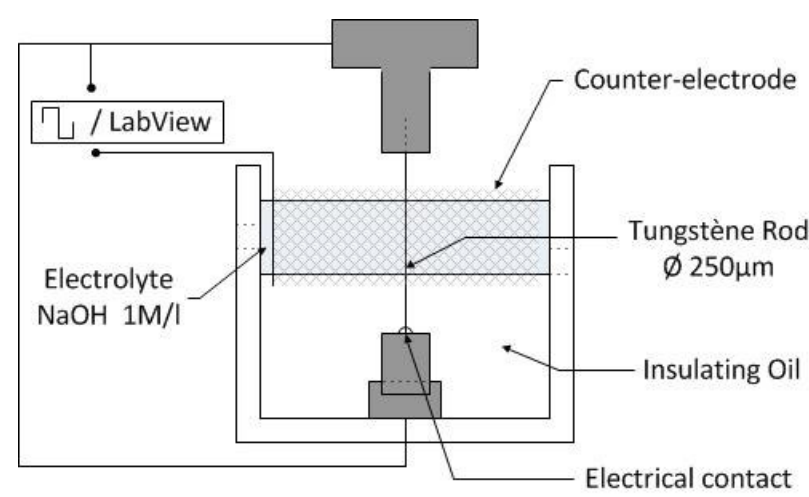

Figure 1: Electrochemical cell

By applying a pulse voltage $(50 \mathrm{~Hz})$ with alternate polarities from a few tens of volts to few volts with appropriate time of application $\left(\mathrm{T}_{\mathrm{ON}}\right)$ and duty cycle $\left(\mathrm{T}_{\mathrm{OFF}} / \mathrm{T}_{\mathrm{ON}}\right)$ (Figure 2 ), a homogeneous etching of the tungsten rod is observed.

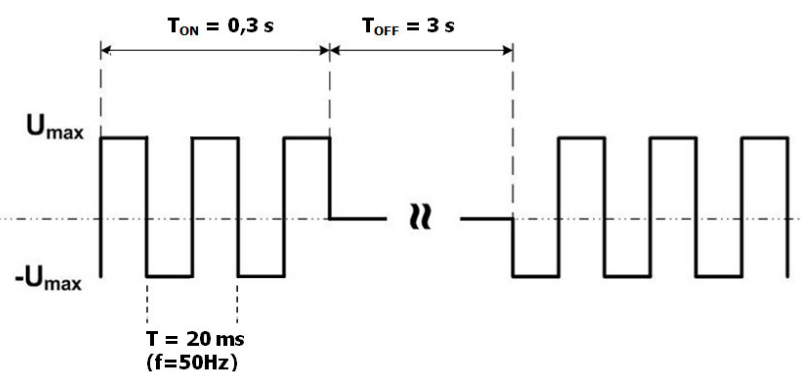

Figure 2: Pulse voltage applied with $T_{O N}-T_{O F F}$ phases

Electronic hardware and Labview interface have been developed to perform successive etching steps as reported in Table 1 . with the control of applied voltage $\mathrm{U}$, application time $\mathrm{T}_{\mathrm{ON}}$, duty cycle and etching time. The result is the progressive thinning of the rod as depicted schematically in Figure 3.

\begin{tabular}{|l|c|c|c|c|c|}
\hline & $\begin{array}{c}\text { Voltage } \\
(\mathrm{V})\end{array}$ & $\begin{array}{c}\text { Current } \\
(\mathrm{mA})\end{array}$ & $\begin{array}{c}\text { Etching time } \\
(\mathbf{s})\end{array}$ & $\begin{array}{c}\mathrm{T}_{\text {oN }} \\
(\mathbf{s})\end{array}$ & $\begin{array}{c}\mathbf{T}_{\text {off }} \\
(\mathbf{s})\end{array}$ \\
\hline Step 1 & \pm 30 & 750 & 700 & 0.3 & 3 \\
\hline Step 2 & \pm 15 & 300 & 500 & 0.3 & 3 \\
\hline Step 3 & \pm 7.5 & 100 & 300 & 0.3 & 3 \\
\hline Step 4 & \pm 3.5 & 20 & 150 & 0.3 & 3 \\
\hline
\end{tabular}

Table 1: The electrochemical etching of the tungsten rod in 4 steps

Before Step 1, the rod is vertically translated until the electrical contact (Figure 3a). At the end of Step 1, the lower part of the rod (in the dielectric) is unchanged whilst the intermediate part (in the electrolyte) is made thinner (Figure 3b). Of course the upper part of the rod in the air is unchanged. So altogether the rod shape is like a dumb-bell. Then steps 2-4 are performed with a series of decreasing voltages to thin down the central part of the rod (Figure 4c) whilst keeping its cylindrical shape. At the end, once the central part has reached the targeted diameter, the rod is translated upward in order to place the lower part of the dumb-bell in the electrolyte. A cut off is applied with a small voltage during a short time in order to remove the lower part of the dumb-bell (Figure 4d).

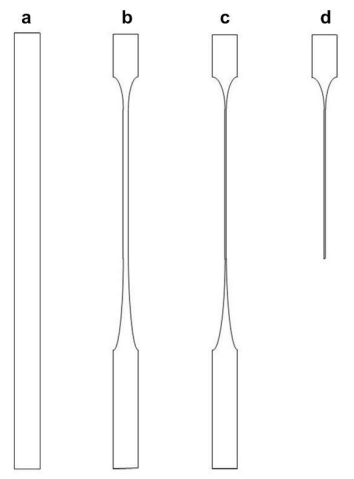

Figure 3: Schematic view of the rod during the different etching steps

\subsection{EXPERIMENTAL RESULTS}

Figure 4 shows the experimental results according to the parameters of Table 1:

- The original rod (Figure 4a).

- The rod after Steps 1-4 (Figure 4b).

- The tool after final cut off showing a diameter of $26 \pm 2$ $\mu \mathrm{m}$ along $400 \mu \mathrm{m}$ (Figure $4 \mathrm{c}$ ).

This tool fabrication process is fully automated and takes about 30 minutes. It is performed without any mechanical machining in a small electrochemical reactor $(5 \times 3 \times 3 \mathrm{~cm})$ with simple and low cost electronics.

It is important to note that Figure 4 (which is included here only for a good understanding of the process) is a collection of about 40 pictures per view. For each view, the electrode is translated up outside the vat so as to take a picture in the air with a Zoom 6000 Navitar with long working distance objective and $1 / 2$ " Sony CCD camera. 
All measurements (diameter, length) are performed at the highest magnification.

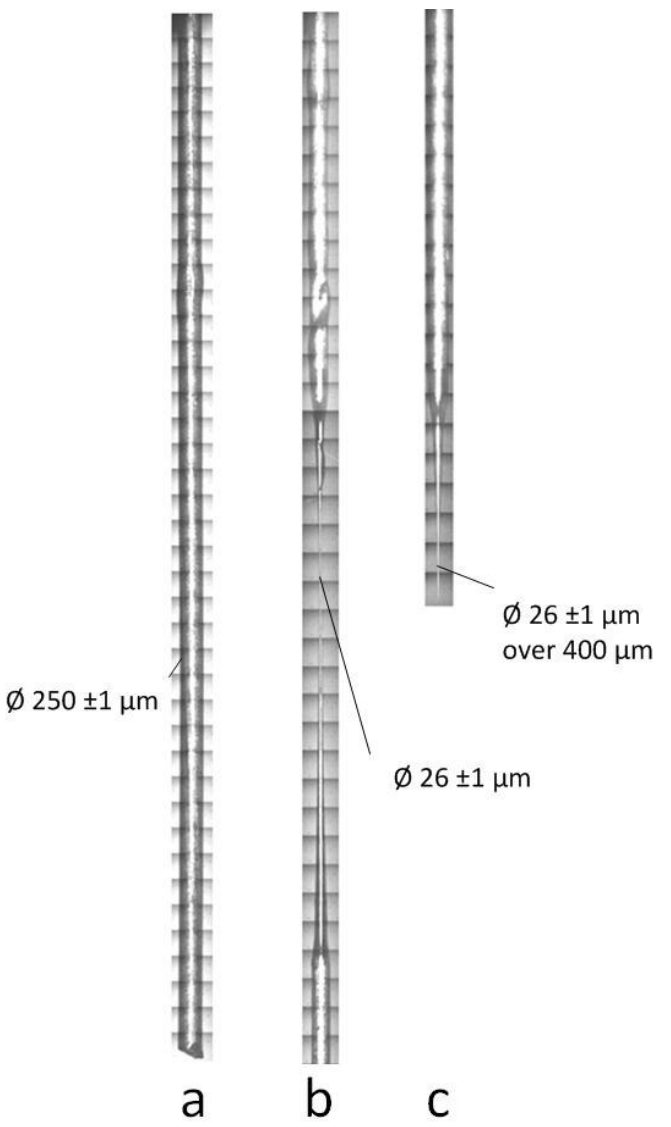

Figure 4: (a) Original rod (b) After the 4 etching steps of Table 1 (c) After cut-off

\section{EDM Machining}

With the tool shown in Figure 4c, $\mu$ EDM machining was performed with a RC circuit for discharge generation (Figure 5). The voltage applied between the electrode and the piece (stainless steel $316 \mathrm{Ti}$ ) was $100 \mathrm{~V}$. The rod was covered with a flow of water, which served as a dielectric. The electrode was moved downward and the part was moved horizontally by stepper motors with a resolution of $2.5 \mu \mathrm{m}$. At this stage of development (proof of concept), only a set of 3 grooves was machined per trial.

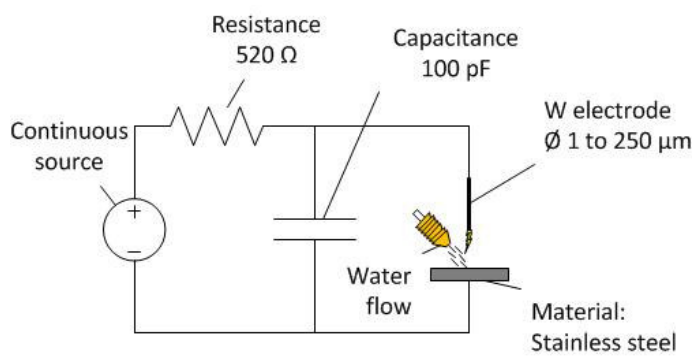

Figure 5: RC-circuit for $\mu E D M$ machining
The grooves made with the electrode are shown in Figure 6a. The height of the grooves has been estimated to $50 \pm 5 \mu \mathrm{m}$ with an Olympus optical microscope BX51M. The width at the bottom of the part is about $26 \pm 1 \mu \mathrm{m}$ (close to the tool diameter) whilst the width at the top of the part is $70 \pm 1 \mu \mathrm{m}$.

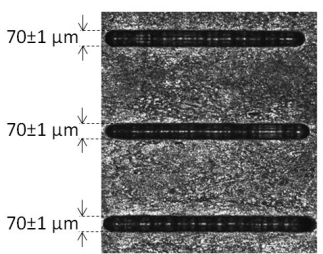

a

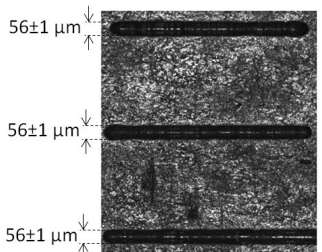

b
Figure 6: (a) View of the grooves after $\mu E D M$ machining with the tool of Figure 4c (optical microscope) (b) View of another set of grooves after machining with the tool of Figure $7 b$

\section{TOOL REGENERATION}

After this first $\mu$ EDM machining step, the tool was imaged and the result is shown in Fig 7a. The wear of the electrode is observed: the electrode length has been reduced from 400 to $240 \mu \mathrm{m}$.

As explained above, the electrode can be regenerated by placing it back to the tool fabrication place with the stepper motor. The regeneration phase is performed with $\pm 7 \mathrm{~V}$ at $50 \mathrm{~Hz}$ (Ton: $0.3 \mathrm{~s}$; Toff: $3 \mathrm{~s}$ ). The result is shown in Figure $7 \mathrm{~b}$. The conical effect has been significantly reduced: the tool diameter is now $20 \pm 1 \mu \mathrm{m}$ over $600 \mu \mathrm{m}$.

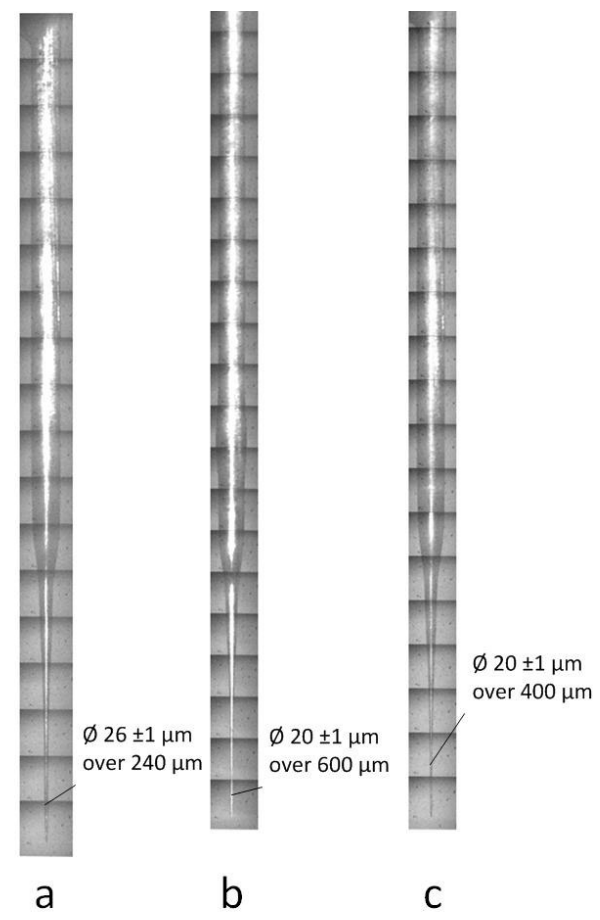

Figure 7: (a) Tool after first $\mu E D M$ machining showing tool wear (b) Regenerated micro-tool (c) Tool after second $\mu E D M$ machining 
The tool of Figure $7 \mathrm{~b}$ has been re-used for a second $\mu$ EDM machining step with the results shown in Figure $6 \mathrm{~b}$. The width of the machined grooves has been reduced: $56 \pm 1 \mu \mathrm{m}$ at the top and $20 \pm 1 \mu \mathrm{m}$ at the bottom of the grooves. After machining the tool has a diameter of $20 \pm 1 \mu \mathrm{m}$ over $400 \mu \mathrm{m}$. (Figure 7c).

\section{MICROMETRIC TOOLS}

By adjusting the parameters of table 1, it is possible to decrease the tool diameter. As a first example Figure 8 shows an optical view of tool with $4 \pm 0.5 \mu \mathrm{m}$ diameter and $320 \mu \mathrm{m}$ length. Figure 9 shows a SEM view of the tip of the tool.

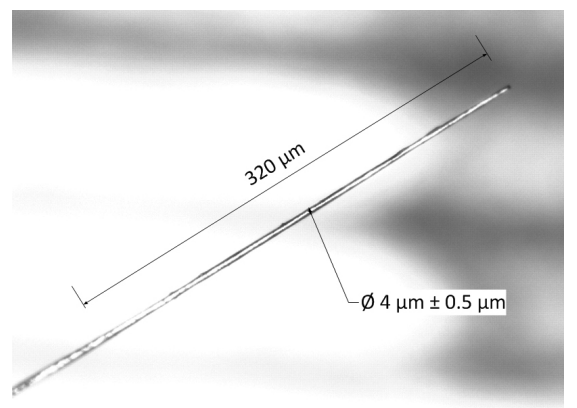

Figure 8: Optical view of a tungsten electrode with $4 \mu \mathrm{m}$ diameter

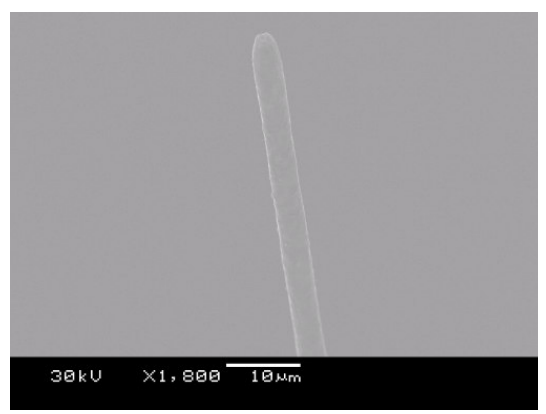

Figure 9: SEM view of the end of the tip of figure 8

In addition, it is possible also to obtain tools with a diameter in the micrometric range. Figure 10 shows a tool with a diameter of about $1 \mu \mathrm{m}$ and a length of 15 $\mu \mathrm{m}$. At this scale no residual stress was observed probably because of the chemical nature of the fabrication process (electrochemical dissolution).

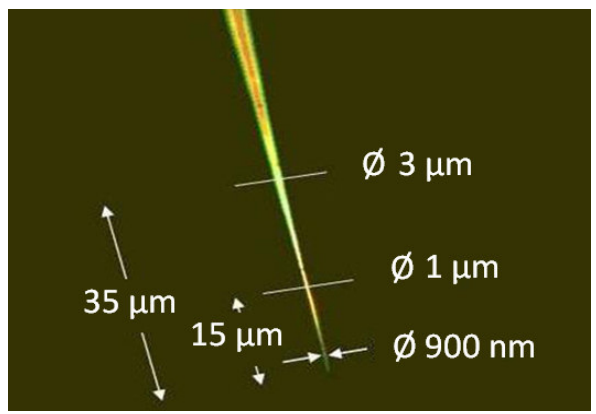

Figure 10: Optical view of a tungsten tool with a diameter in the micrometric range over $15 \mu \mathrm{m}$.

\section{CONCLUSION}

Different examples of manufacturing of tungsten microtools have been reported with diameter ranging from 1 $\mu \mathrm{m}$ to $26 \mu \mathrm{m}$ and aspect ratio ranging from 15 to 20 . Preliminary examples of $\mu \mathrm{EDM}$ machining have been also reported with the $26 \mu \mathrm{m}$ diameter tool. Further optimization will be necessary to take full advantage of the miniaturized tools for $\mu$ EDM machining.

However, these tools have been obtained in 30 minutes with a process which has fully been integrated in our milling $\mu$ EDM machine. The tool fabrication is a low cost and automated technique performed with simple electronics. This opens new perspectives especially in the field of $\mu \mathrm{EDM}$ milling which requires very thin and long tools which are extremely fragile. Future research will concern the fabrication of tools with submicrometric diameter as well as the increase of the aspect ratio. The question of the residual stress after fabrication of the tools will be also investigated.

In addition, in situ electrochemical regeneration of the tool has been also demonstrated in this work. It is known that the tool wear is of paramount importance in the milling EDM process and is difficult to compensate because of the difference of surface between the tool and the part. Therefore fast and automated regeneration of the tool could be of great help to simplify the tool wear compensation algorithm.

\section{ACKNOWLEDGEMENT}

The work was financed by grant L356 of Lyon Science Transfert (with support from the PRES of Lyon, the ANR, the FEDER, the Région Rhône Alpes and the Grand Lyon). G. Girardin acknowledges the support of the CNRS and DGA for a PhD grant.

\section{REFERENCES}

[1] Benilov A, Skryshevsky V, Robach Y, Cabrera M: Micro and nano electrical discharge machining in microfluidics and micro nanotechnology. International Journal of Material Forming 1, Sup 1, 1315-1318, 2008. DOI 10.1007/s12289-008-0145-6.

[2] Lim H.S., Wong Y.S., Rahman M., Edwin Lee M.K.: A study on the machining of high-aspect ratio micro-structures using micro-EDM. Journal of Materials Processing Technology 140: 318-325, 2003.

[3] Masuzawa T., Fujino M., Kobayashi K., Wire electro-discharge grinding for micro-machining. Annals of CIRP 34(1): 431-434, 1985.

[4] Kawakami T, Kunieda M: Study on Factors Determining Limits of Minimum Machinable Size in Micro EDM. CIRP Annals - Manufacturing Technology 54: 167-170, 2005.

[5] Cabrera M: Machine et procédé d'usinage d'une pièce par micro-électroérosion. French Patent Application $\mathrm{n}^{\circ}$ FR0805148 (19/09/2008) and PCT/EP2009/061683. 